\title{
Lethal fetal cerebrorenogenitourinary agenesis/hypoplasia syndrome
}

INSERM

\section{Source}

INSERM. (1999). Orphanet: an online rare disease and orphan drug data base. Lethal fetal cerebrorenogenitourinary agenesis/hypoplasia syndrome. ORPHA:439897

Lethal fetal cerebrorenogenitourinary agenesis/hypoplasia syndrome is a rare, genetic developmental defect during embryogenesis malformation syndrome characterized by intrauterine growth restriction, flexion arthrogryposis of all joints, severe microcephaly, renal cystic dysplasia/ag enesis/hypoplasia and complex malformations of the brain (cerebral and cerebellar hypoplasia, vermis, corpus callosum and/or occipital lobe agenesis, with or without arhinencephaly), as well as of the genitourinary tract (ureteral agenesis/hypoplasia, uterine hypoplasia and/or vaginal atresia), leading to fetal demise. 